\title{
EFFECT OF ROBOT UTTERANCES USING ONOMATOPOEIA ON COLLABORATIVE LEARNING
}

\author{
Felix Jimenez ${ }^{1}$, Masayoshi Kanoh ${ }^{2}$, \\ Tomohiro Yoshikawa $^{1}$, Takeshi Furuhashi ${ }^{1}$ and Tsuyoshi Nakamura ${ }^{3}$ \\ ${ }^{1}$ Graduate School of Engineering, Nagoya University \\ Furo-cho, Chikusa, Nagoya, 464-8603, Aichi, Japan \\ ${ }^{2}$ School of Engineering, Chukyo University \\ 101-2 Yagoto Honmachi, Showa-ku, Nagoya, 466-8666, Aichi, Japan \\ ${ }^{3}$ Graduate School of Engineering, Nagoya Institute of Technology \\ Gokiso-cho, Showa-ku, Nagoya, 466-8555, Aichi, Japan
}

\begin{abstract}
We investigated the effect of robot's utterances using onomatopoeia in collaborative learning. The robot was designed to provide encouragement using onomatopoeia when students are given problems to be solved issued by a learning system. Eight college students used a mathematics learning system with a robot for three weeks and then took exams. The results indicated that the robot using utterances with onomatopoeia could comfort learners more than the robot without onomatopoeia. It suggests that the robot that praises or comforts using onomatopoeia helps learners maintain their motivation in collaborative learning.
\end{abstract}

\section{Introduction}

With the growth in robot technology, more robots are now supporting learning. For example, one robot supports the learning of students as a peer tutor [1] whereas in another study, a robot helps students improve their English [2]. Interaction between robots and humans promotes a more realistic learning experience, which could lead to making students more interested in learning [3]. Moreover, a robot's recommendations are taken more seriously than those displayed on a screen agent. For example, Shinozawa and co-workers [4] experimentally confirmed through quantitative evaluation that the degree of recommendation effect firmly depends on the interaction environment. There results showed that a three-dimensional body has an advantage when the interaction environment is a threedimensional space. This suggests when a robot describes an object that exists in real space to a human.
In addition, Bainbridge [5] explored how a robot's physical or virtual presence affects unconscious human perception of the robot as a social partner. Participants collaborated on simple bookmoving tasks with either a physically-present humanoid robot or a video-displayed robot. Each task examined a single aspect of interaction, i.e., greetings, cooperation, trust, and personal space. Participants readily greeted and cooperated with the robot in both the situations. However, participants were more likely to fulfill an unusual instruction and afford greater personal space to the robot in the physical situation than in the video-displayed situation. Therefore, a robot's physical presence has a beneficial effect on learning and problem solving.

Most studies have focused on different robot behaviors and investigating the effects. For example, Koizumi [6] used a series of Lego-block building classes run by a robot to promote spontaneous collaboration among children. Robots not only man- 


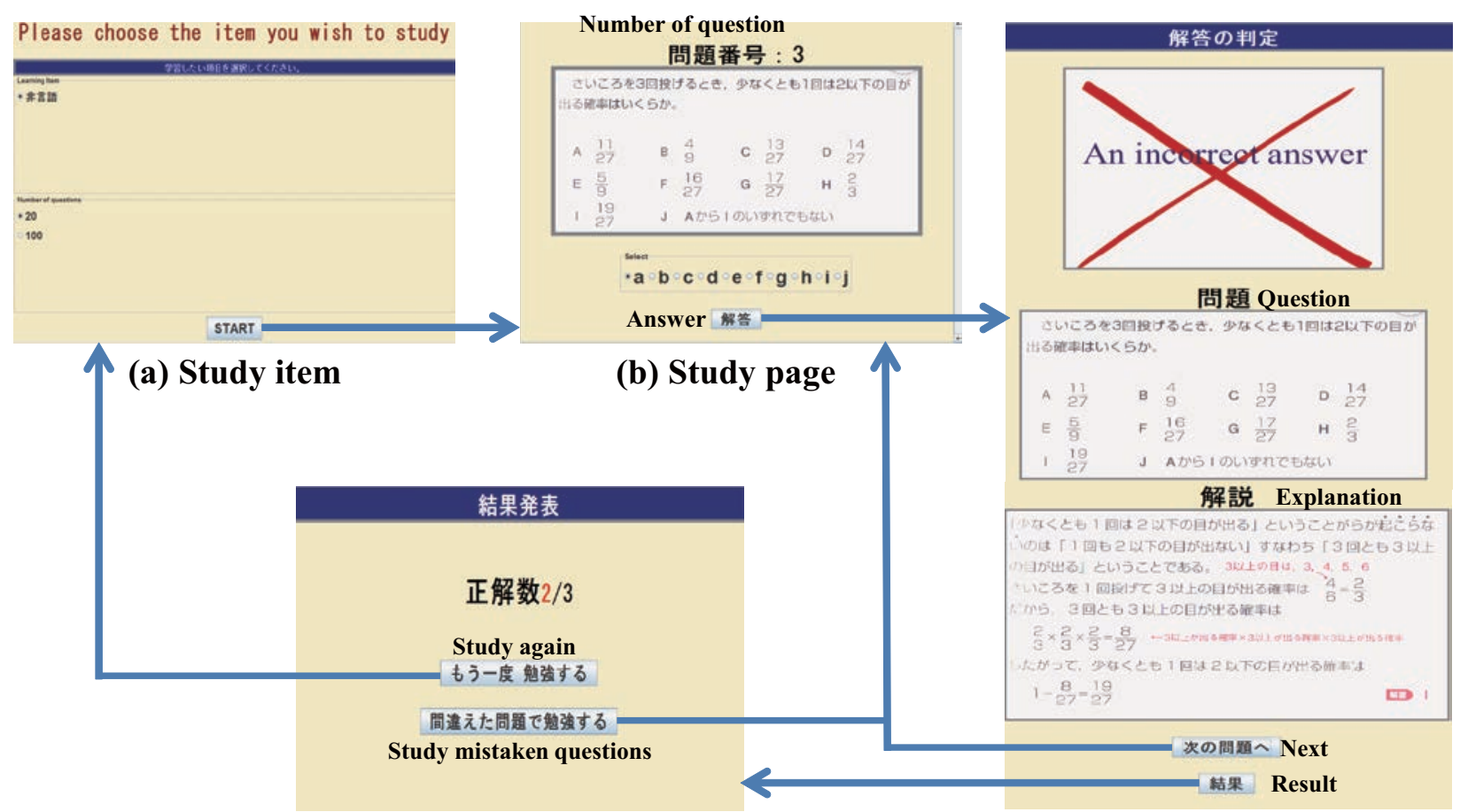

(d) Study result

(c) Judgment

Figure 1. Learning System

age collaborative learning between children but also have positive social relationships with children by praising their efforts. These experimental results suggest that robots promote spontaneous collaboration among children and improve their enthusiasm for learning. Moreover, Tanaka [7] reported on a robot that can promote learning by teaching children. He conducted an experiment at an English language school for Japanese children (4-8 years old). He introduced a small humanoid robot in situations where children completed tasks issued by their teacher. While children were completing the task, the robot intentionally made a mistake. However, because only few studies have focused on robot utterances, we do not know how they affect learning and motivation.

Education studies focusing on teacher utterances have reported that teacher utterances affect learners. For example, if a teacher encourages a learner faced with completing a task, the teacher can prompt the learner to increase their motivation [8]. Teacher utterances using onomatopoeia has recently gained attention. Onomatopoeia is a sensuous representation of an object, sound, or state. It can express an object that has a clear, realistic sensation [9]. Physical education stud- ies have suggested that teachers who instruct using onomatopoeia prompt learners to learn content and increase their motivation [10]. A study that analyzed teacher utterances in a nursing school reported that a teacher uses onomatopoeia when explaining instructional content. This suggests that onomatopoeia can stress teacher's utterances and increase learner motivation [11][12]. Therefore, we believe that utterances with onomatopoeia are more effective in learning than those without onomatopoeia. We also believe that onomatopoeia can be used for robot utterances.

Here, we investigated the effect of a robot's utterances with onomatopoeia on learners in collaborative learning. We compared such utterances with normal utterances. The robot was designed to provide encouragement using onomatopoeia when learners are faced with solving a problem issued by a learning system. For example, when learners successfully solve a problem, the robot praises the learner's success by uttering, "You're gungun (really) improving." On the other hand, when learners cannot solve the problem, the robot comforts the learners by uttering, "Keep up the kibikibi (good) work." 
This paper consists of five sections. The second section explains the learning system used by the robot and learners. The third section describes the robot used in this study. The fourth section evaluates the involvement of the robot after describing its effect on learning, and the final section is the discussion.

\section{Onomatopoeia}

Onomatopoeia is a generic term for an "echoic word" or "imitative word." If you utilize Japanese verbs including onomatopoeia, you can easily express what you would like to communicate. For example, "quickly walking" or "trotting" can be expressed as "sakusaku" in Japanese and "plodding" can be expressed as "tobotobo." Such examples of onomatopoeia use sounds that are independent of linguistic meaning and are known as sound symbolism. The advantages of sound symbolism in a learning environment are that it transcends languages and creates a richer impression on learners than words alone. Therefore, onomatopoeia can more fully express reality than general vocabulary.

\section{Overview of learning system}

We used a learning system (Fig. 1) for mathematical problems called "Synthetic Personality Inventory 2 (SPI2)," which is used as a recruitment test for employment. The mathematical problems are junior high school level such as profit or loss calculations and payment of fees. Therefore, college students did not require additional knowledge to solve the problems. The problems in the learning system were created by consulting the "2014 SyuSyokukatudou no Kamisama no SPI2 mondaisyu (in Japanese) [13]."

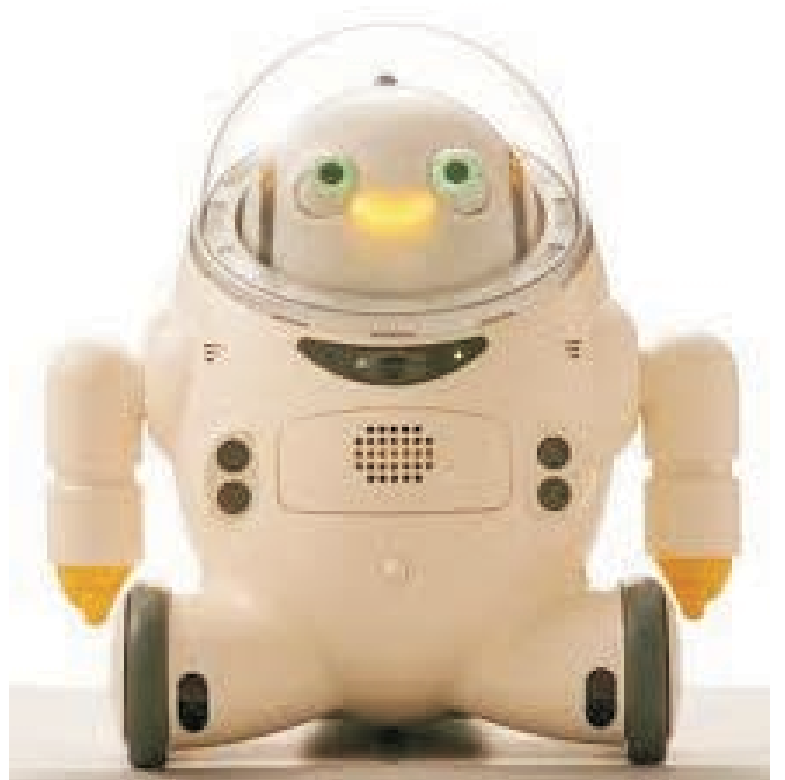

Figure 2. Apperance of Ifbot

First, learners enter their account number to $\log$ in. A menu of study items is shown on the system (Fig. 1(a)). The study items are mathematical problems. The column from which the number of problems is chosen is shown under the study items. When the learner selects " 20 ," 20 problems are displayed at random. When " 20 " is selected again, 20 different problems are displayed. This is continued until all the problems are completed (100 problems). This enables learners to solve the problems within the selected study item. When the learner selects the study item and the number of problems, the learning screen (Fig. 1(b)) appears and the learning process starts. The learner provides an answer to the problem from the selection list. After the answer is entered, the system displays whether it is correct, as shown in Fig. 1(c). When the learner selects "Next" (Fig. 1(c)), the system moves on to the next problem. When the learner selects "Result" (Fig. 1(c)) or solves all the problems, the system moves on to the results page (Fig. 1(d)). This page presents the number of correct and incorrect answers. When the learner selects "Study again," a menu of learning items is displayed (Fig. 1(a)). When the learner selects "Study mistaken problems," the study page presents problems that were answered incorrectly (Fig. 1(b)). 
(e) Happy

expression 1

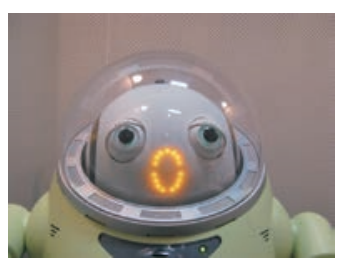

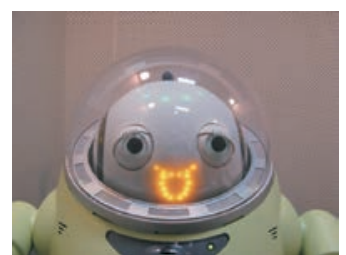

(f) Happy

expression 2
Figure 3. Examples of happy expression with Ifbot

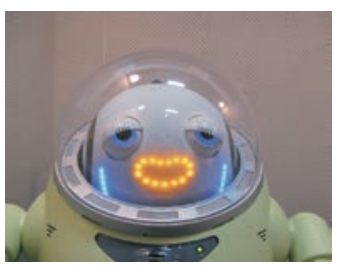

(g) Unhappy expression 1

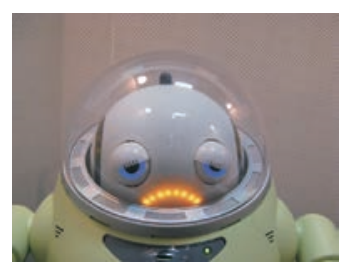

(h) Unhappy expression 2
Figure 4. Examples of unhappy expressions with Ifbot

\section{Overview of robot}

\subsection{Robot}

We used Ifbot (Fig. 2), which is a conversation robot. Ifbot can be used as an English learning robot to promote more effective learning [14]. It can also express various expressions. We implemented the learning system inside Ifbot and configured the learning environment so that Ifbot and the student could face the monitor and learn together.

Table 1. Example of Ifbot's utterances

\begin{tabular}{|l|l|l|}
\hline & Normal utterance & Onomatopoeia utterance \\
\hline \multirow{3}{*}{ Praise } & $\begin{array}{l}\text { You're improving. } \\
\text { That's an improvement. } \\
\text { You certainly did today. }\end{array}$ & $\begin{array}{l}\text { You're } \text { gungun improving. } \\
\text { That's patto an improvement. } \\
\text { You certainly did balibali today. }\end{array}$ \\
\hline \multirow{3}{*}{ Yncouragement } & $\begin{array}{l}\text { Keep up the work. } \\
\text { Let's do our best } \\
\text { Keep working on it. }\end{array}$ & $\begin{array}{l}\text { Keep up the } \text { kibikibi } \text { work. } \\
\text { Let's do our } \text { dondon best } \\
\text { Keep gangan } \text { working on it. }\end{array}$ \\
\hline
\end{tabular}

\subsection{Robot's utterances}

We examined whether learners can learn from robot's utterances in collaborative learning. Therefore, the robot did not use functions that enabled its direct interaction with humans such as voice recognition. The robot acted in accordance with the screen of the learning system. Recent studies have reported that teacher encouragement affects learn- ing motivation when learners solve problems [15]. Moreover, an agent's sympathy has been reported to improve the motivation of learners [16]. Therefore, Ifbot was designed to display a happy or unhappy expression and utter phrases of encouragement when learners solved a problem (Fig. 1(b)) and display the results (Fig. 1(c)). When learners could not solve the problem, Ifbot expressed sadness. Utterances included onomatopoeia and were created by consulting recent education studies [10] [17].

(1) Praising motion

When learners correctly solve a problem, the robot displays a happy expression, as shown in Figs. 3 (a) and (b), and utters, "You're gungun (really) improving (Table 1(right))."

(2) Encouraging motion

When learners cannot solve a problem, the robot displays an unhappy expression by beginning to shed tears, as shown in Figs. 3 (a) and (b), and utters, "Let's do our dondon (more) best (Table 1(right))."

These two motions are performed when the learning screens (Fig. 1(c)) are shown.

\section{Question}

ある商品に仕入れ值の3割の利益を見込んで5200円の定価 をつけたが, 売れなかったので, 定価の1剖引で売った。この ときの利益はいくらか。

\begin{tabular}{|c|c|c|c|c|c|c|c|}
\hline \multicolumn{8}{|c|}{ Answer list } \\
\hline A & 460円 & B & 5004 & c & 550 \% & D & $600 \mathrm{H}$ \\
\hline E & 630円 & $\mathrm{F}$ & 680円 & G & $700 \mathrm{H}$ & $H$ & 720\% \\
\hline 1 & $780 \%$ & $\mathrm{~J}$ & $\mathrm{~A} / 2=1$ & कL: & 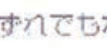 & S. (h) & \\
\hline
\end{tabular}

Figure 5. SPI test

\section{Examination}

We conducted two examinations. One was to investigate the effect of Ifbot's utterances using onomatopoeia on learning. Another was to evaluate if Ifbot's actions were able to interest the learners in learning. 


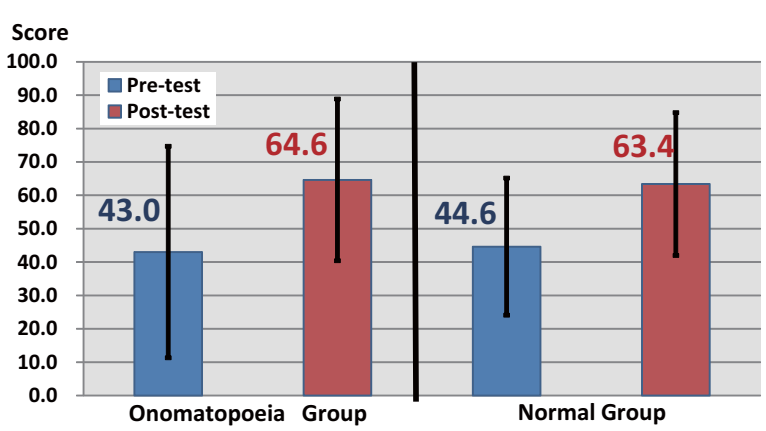

Figure 6. Average scores for Pre and Post-test of each group

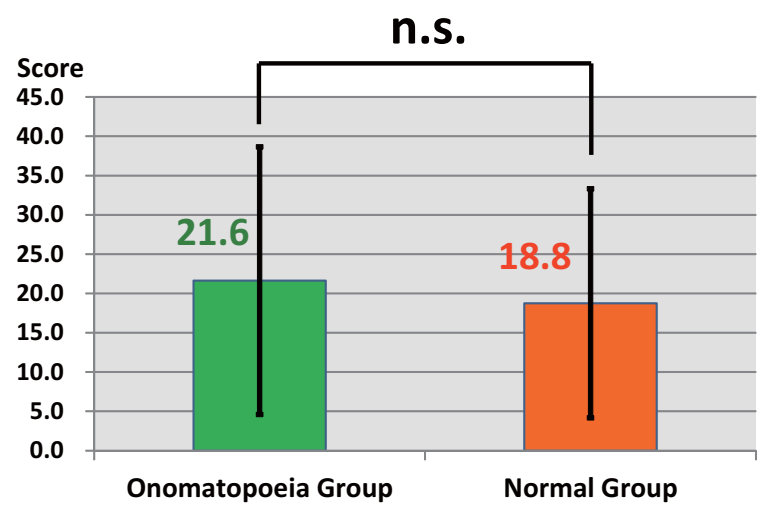

Figure 7. Average learning gains of each group

\subsection{Investigating effect on learning}

\subsubsection{Method}

This experiment was conducted to determine the effect of Ifbot's utterances with onomatopoeia on learning in two groups of learners. In both the groups, learners learned with Ifbot. However, in one group, the robot praised and comforted with onomatopoeia. This group was called the Onomatopoeia Group. In the other group, the robot praised or comforted without onomatopoeia. This group was called the Normal Group. Sixteen college students participated in the experiment. Both the groups consisted of eight learners. The learners learned mathematics on the learning system for 40 minutes, three times a week for three weeks for a total of 9 times.

\subsubsection{Evaluation}

The aim of the evaluation was to determine the difference in learning gains between the Ono- matopoeia Group and Normal Group. The learning gains were calculated by subtracting the pre-test scores from the post-test scores. Each pre-test and post-test was presented as an SPI test, as shown in Fig. 5. The SPI test was based on problems in the learning system and consisted of 95 problems. The analysis method involved a t-test. A significant difference is permitted if the $p$ value is under the significance level of $5 \%$.

\subsubsection{Results}

The average pre-test and post-test scores are shown in Fig. 6. The average learning gains scores are shown in7. Both Figs. 6 and 7 show the scores of the Onomatopoeia Group on the left and those of the Normal Group on the right. The scores of learners in the Onomatopoeia Group were better than those in the Normal Group. We also conducted a t-test to determine how effectively learners learn the questions using the learning gains scores of each group, as shown in Fig. 7. The results indicate that there was no significant difference $(t=0.3, d f=$ $14, p=0.37)$. Therefore, there was no difference in the effect on learning between the Onomatopoeia Group and Normal Group.

\subsection{Examination to evaluate robot's action}

\subsubsection{Method}

The robot's action was evaluated using the semantic differential scale method (SD method) [18]. The SD method is used to evaluate the meaning of objects and concepts. Recently, the SD method has been used in robotics. For example, Ogata [19] used the SD method for evaluating the interaction between robots and humans. Kanda [20] used the SD method involving 28 adjectives for psychological evaluation experiments on robotic interaction. We used the SD method involving the following four adjectives, "approach?able," "sociable," "fulfilling," and "pleasurable." The SD method is shown in Fig. 8. The evaluation values are defined in the top left part as "- 3 " and increase by one as they progress to the right. We used the MannWhitney $U$-test. A significant difference is permitted if the $\mathrm{p}$ value is under the significance level of $5 \%$. 


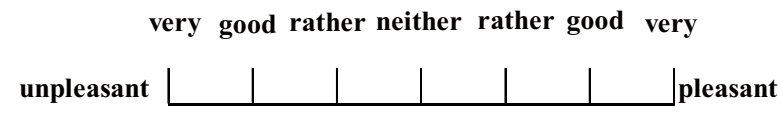

Figure 8. SD method used in this study

Table 2. SD method results

\begin{tabular}{cc|c|c}
\multicolumn{2}{c|}{ Adjective } & Onomatopoeia Group & Normal Group \\
\hline unpleasant & pleasant & $1.38( \pm 1.1)$ & $0.13( \pm 0.8)$ \\
stuffy & sociable & $1.25( \pm 1.1)$ & $0.25( \pm 1.5)$ \\
depression & fulfilling & $0.63( \pm 0.5)$ & $-0.75( \pm 1.2)$ \\
unapproachable & approachable & $0.75( \pm 1.1)$ & $1.75( \pm 1.0)$ \\
\hline
\end{tabular}

\subsubsection{Results}

The average evaluation values of each group are listed in Table 2, and the analysis results are listed in Table 3. The results indicate that the values of learners in the Onomatopoeia Group were better than those in the Normal Group for "sociable," "pleasurable," and "fulfilling," whereas the values of "approachable" for the learners in the Normal Group were better than those in the Onomatopoeia Group. The Mann-Whitney $U$-test results indicate that there was a significant difference between the Onomatopoeia Group and Normal Group in the criteria of "pleasurable" and "fulfilling." Therefore, the learners in the Onomatopoeia Group were more fulfilled than those in the Normal Group.

Table 3. Result of analysis

\begin{tabular}{cc|c|c}
\multicolumn{2}{c|}{ Adjective } & $U$ & $p$ value \\
\hline unpleasant & pleasant & 17 & 0.02 \\
stuffy & sociable & 20 & 0.19 \\
depression & fulfilling & 10 & 0.01 \\
unapproachable & approachable & 11.5 & 0.09 \\
\hline
\end{tabular}

\section{Discussion}

The results suggest that our robot encourages learners. However, there was no difference in learning between utterances using onomatopoeia and normal utterances.

Recent education studies in which teachers used onomatopoeia have suggested that onomatopoeia can help stress teacher's utterances [11] [12]. We believe that the same result is possible with robots.

The learning period in our study was short, only three weeks, which is one possible reason that there was no difference in the effect on learning between utterances using onomatopoeia and normal utterances. Recent education studies have shown that it takes time for increase in motivation to be reflected in the learning of students [21]. However, we found that the learning gains of learners in the Onomatopoeia Group were greater than those in the Normal Group, as shown in Fig. 7.

\section{Conclusion}

We investigated the effect of robot's utterances using onomatopoeia on learners in collaborative learning. We evaluated the effect of utterances using onomatopoeia by comparing them with normal utterances. The robot was designed to praise or comfort with onomatopoeia when learners were faced with solving problems issued by a learning system. For example, when learners correctly solved a problem, the robot praised the learners by uttering, "You're Gungun (really) improving." When learners could not solve a problem, the robot comforted the learners by uttering, "Keep up the Kibikibi (good) work."

These results suggest that the robot encouraged learners. However, there was no difference in the effect on learning between groups where utterances using onomatopoeia and normal utterances were used.

We are currently developing a robot that praises or comforts using adjectives and adverbs for comparing the effect on learning between utterances with and without onomatopoeia. We also plan to conduct a long-term experiment.

\section{References}

[1] T. Kanda, T. Hirano, D. Eaton and H. Ishiguro : "Interactive robots as social partners and peer tutors for children: A field trial," Hum-Comout. Interact., vol.10, No.1, pp.61-84, 2004.

[2] O.H. Kwon, S.Y. Koo, Y.G. Kim and D.S. Kwon: "Telepresence robot system for english tutoring," IEEE Workshop on Advanced Robotics and its Social Impacts, pp.152-155, 2010.

[3] T. Kand: "How a communication Robot Can Contribute to Education (in Japanese)," Journal of 
Japanese Society for artificial Intelligence, Vol.23, No.2, pp.229-236, 2008.

[4] K.Shinozawa, F.Naya, J.Yamato and K.Kogure: "Differences in effect of robot and screen agent recommendations on human decision-making," International Journal of Human-Computer Studies, Vol.62, No.2, pp.267-279, 2005.

[5] W.A. Bainbridge, J. Hart, E.S. Kim and B. Scassellati: "The effect of presence on human-robot interaction," IEEE International Symposium on Robot and Human Interactive Communication, pp.701706, 2008.

[6] S. Koizumi, T. Kanda and T. Miyashita: "Collaborative learning experiment with social robot (in Japanese)," Journal of the Robotics Society of Japan,Vol.29, No.10, pp.902-906, 2011.

[7] F. Tanaka: "Social robotics research and its application at early childhood education (in Japanese)," Journal of the Robotics Society of Japan, Vol.29, No.1, pp.19-22, 2011.

[8] H. Namiki: "Kotobakake no kouka no zikkenkekka kara (in Japanese)," Child psychology, Vol.47, No.5, pp.474-477, 1993.

[9] T. Komatsu and H. Akiyama: "Expression system of onomatopoeias for assisting users' intuitive expressions (in Japanese)," The Journal of the Institute of Electronics, Information and Communication Engineers A,Vol.J92-A, No.11, pp.752-763, 2009.

[10] Y.Fujino, M.Kikkawa and Y.Sagisaka: "A collection of onomatopeias in japan sports (in Japanese)," Proc Oriental Cocosda, pp.160-164, 2003.

[11] M. Takano and M. Udo: "Onomatopoeia in the utterances of teachers at special schools (in Japanese)," The Japanese Association of Special Education, Vol.48, No.2, pp.75-84, 2010.
[12] M. Takano and M. Udo: "Contribution of onomatopoeia to educational support for children with severe mental retardation (in Japanese)," The Journal of School Education,Vol.19, pp.27-37,2007.

[13] H. Shinagawa: "2014 SyuSyokukatudou no Kamisama no SPI2 mondaisyu (in Japanese)," UCAN-pub, 2012.

[14] F.Jimenez and M.Kanoh: "Robot that can promote learning by observing in collaborative learning," IEEE International Conference on Systems, Man, and Cybernetics, 2013.

[15] E.B.Hurlock: “An evaluation of certain incentives used in school work," Journal of Education Psychology, Vol.16, pp.145-150, 1925.

[16] H. Nakajima, Y. Moroshima, R. Yamada, S. Kawaji, S. Brave, H. Maldonado and C. Nass: "Social Intelligence in a Human-Machine Collaboration System : Social Responses of Agents with Mind Model and Personality (in Japanese)," Journal of Japanese Society for Artificial Intelligence,Vol.19, No.3, pp.184-196, 2004.

[17] M.Ono: "Giongo Gitaigo 4500 Nihongo Onomatope Ziten (in Japanese)," Syougakkan, 2007.

[18] C.E.Osgood: "Studies on the generality of affective meaning systems," American Psychologist, Vol.17, pp.10-28, 1962.

[19] T. Ogata and S. Sugano: "Experimental Evaluation of the Emotional Communication between Robots and Humans,' ISCIE Journal 'Systems, Control and Information, Vol.13, No.12, pp.566-574, 2000.

[20] T. Kanda, H. Ishiguro and T. Ishida: "Psychological Evaluation on Interactions between People and Robot (in Japanese)," Journal of the Robotics Society of Japan, Vol.19, No.3, pp.362-371, 2001.

[21] Y. Miyake and N. Miyake : "Pedagogical psychology (in Japanese)," Foundation for the Promotion of The Open University of Japan, 2012. 